\title{
Analogies in Entity Risk Mechanics
}

\author{
Milík Tichý \\ Department of Civil Engineering, Czech Technical University \\ Prague 16629, Czech Republic \\ E-mail: milik.tichy@volny.cz
}

Received 12 October 2013

Accepted 23 April 2014

\begin{abstract}
Companies exposed to hazards can be paralleled to building and engineering Structures subjected to physical loads; see. Important analogies can be identified in various specific concepts, e.g., in size effect, instability, fatigue, and in many others.
\end{abstract}

Keywords: entity, structure, company, risk, hazard, risk concern, structural mechanics, size effect, instability

\section{Introduction}

In (M. Tichý, 2012) basic analogies between notions of Structural Mechanics and Risk Analysis were shown. For this purpose, Structure subjected to loads was paralleled to Company exposed to hazards. Similarly as loads create stress and strain in Structures, risk, Rs, and risk concern, $\mathrm{Cn}$, are generated in Companies whenever hazards are identified by individuals or groups involved directly or indirectly in Company's activities.

The science of Risk Management is considerably younger than Structural Mechanics. Though the explicit definition of risk dates back to 1718, cf. (M. Tichý, 2012), a systematic theoretical approach started only in 1968. See the seminal paper by (C. Starr, 1969) that moved the risk theory from the space of the games theory and actuarial sciences space to the economic and societal decision making area.

\section{Analogies Discussed}

For the Reader's convenience, basic analogies between loads and hazards identified in (M. Tichý, 2012) are summarized in Table 1. In this paper, the idea of Load/Hazard Analogies is being further developed.
Some specific notions of Structural Mechanics are matched with notions of Company Risk Analysis to show the viability of the analogies concept.

Table 1. Load/Hazard Analogies as identified in (M. Tichý, 2012)

\begin{tabular}{|c|c|c|c|}
\hline Level & $\begin{array}{l}\text { Structural } \\
\text { Mechanics }\end{array}$ & $\rightarrow$ & Risk Analysis \\
\hline External & load, $L$ & $\rightarrow$ & hazard, Hz \\
\hline \multirow[t]{3}{*}{ Internal } & load effect, $F$ & $\rightarrow$ & hazard scenario, $\mathrm{Sc}$ \\
\hline & stress, $\sigma$ & $\rightarrow$ & risk, Rs \\
\hline & strain, $\varepsilon$ & $\rightarrow$ & concern, $\mathrm{Cn}$ \\
\hline Constitutive & stress-strain & $\rightarrow$ & risk-concern \\
\hline law & function $[\sigma, \varepsilon]$ & & function [Rs, Cn] \\
\hline $\begin{array}{l}\text { Governing } \\
\text { requirement }\end{array}$ & $\begin{array}{r}\text { structural } \\
\text { reliability } \\
\text { requirement }\end{array}$ & $\rightarrow$ & $\begin{array}{l}\text { risk acceptability } \\
\text { requirement }\end{array}$ \\
\hline
\end{tabular}

To avoid misunderstandings, it has to be emphasized that, similarly as in (M. Tichý, 2012), behavior of Companies exposed to hazards is being here paralleled to the behavior of load-carrying Structures subjected to physical loads, but definitely not to the behavior of Structures exposed to hazards. Note also that Risk Analysis is not compared with Structural Mechanics; 
they both are undeniably two independent branches of knowledge, which have nothing in common.

At many points of this paper, detailed listings of examples could be given to illustrate the concepts and notions presented. Unfortunately, the number of examples had to be limited. The Reader will surely understand this restriction; space remains thus open for his/her creative imagination.

\section{Review of Concepts and Notions}

In general, the original concept of "risk triplet", introduced by (S. Kaplan \& B. J. Garrick, 1981), is respected by the Author; see also (S. Kaplan, 1997). Risk analysis notions applied in (M. Tichý, 2012), i.e., hazard, hazard scenario, and risk, are used. Upside aspects of risks are not pursued. The meaning and definition of "risk" are not discussed here. "Risk" is a complicated, multidimensional concept. The definition of risk has been recently discussed in a series of papers; see, e.g., (H. Merkelsen, 2011).

Only hazards are being studied here. Note that hazard uncertainties are not identical with risk uncertainties. It happens in Risk Analyses that a hazard of high subjective severity gets paired with a very low risk, owing to very small probabilities of materialization of possible hazard scenarios. Though the value of risk is taken as a starting point of decisions in general, hazard circumstances exist where decisions shall be governed by hazard severity first and foremost. Inversely, it happens that some hazards get overrated at the cost of hazards that remain unobserved.

Recall that in (M. Tichý, 2012) the term "Entity" universally refers to all objects and processes of any kind - tangible, intangible, or mixed. Most Entities are components of Supra-Entities, and, similarly, many Entities are composed of Sub-Entities. Hierarchies of Entities can be thus easily found in whatever framework. A component can be a clearly defined unit in the respective Entity, or a unit spread in the systems. The links between units belong also to the set of Entity components, as well as the respective joints.

Throughout the paper, the summary term Person stands either for individuals or for groups, both of diverse qualities and positions. A Person can be internal, existing in the framework of the Company (e.g., owners, stockholders, CEO, staff, management departments, individual employees, an ad hoc expert team), or external, existing beyond the Company and possessing some permanent or transient relation to it (as, e.g., customers, business partners, lawyers, clients, banks, government).- There of course are several other classifications of Persons; e.g., natural and judicial Persons are distinguished in legal procedures.

Time and space must never be ignored in any analyses. While time has always the same physical quality, several kinds of spaces can be of interest in Risk Analyses. In addition to the traditional space, defined geometrically, a management space, marketing space, operation space, cost space, and others shall be considered, taking into account their specific, time dependent properties.

Modifying attributes like slow/fast/quick, small /large, light/heavy, immediate/brief/long, sudden/ gradual, insignificant/significant and similar shall be, in general, understood as indicative, without any particular quantifiable meaning. E.g., a statement saying that "something is small" shall be examined and assessed in the particular context discussed. Similarly, attributes empirical/exact, must be taken in view of circumstances. Semi-exact and semi-empirical solutions are frequent in any science, except mathematics.

\section{Hazards}

Recall here briefly some general qualities of hazards:

Basically, hazards originate from one of two distinct groups of sources:

(1) anthropogenic sources - hazards come from human activity/non-activity and human decisions/nondecisions (e.g., careless market analyses, insurance fraud, insufficient supervision of employees)

(2) natural sources - hazards come from phenomena independent on human activities (e.g., seismic waves, inclement weather)

Hazards from sources of both origins are frequently interwoven; a typical example: floods in areas where the river flow (nature) is regulated by longitudinal or transversal dams (man).

Hazards can be fully subjective, created and dwelling solely in minds of Persons, or objective, generated in minds by existing or expected phenomena, tangible or not. The boundary between objectivity and subjectivity is in most situations fuzzy.

It is important to stress that a hazard from whatever source, single or mixed, objective or subjective, identified in the risk analysis of a project, may never get materialized during the lifetime of the Entity at all. 
Anyway, hazards of any kind breed feelings of uncertainty, risk concern, and possibly fear or panic. Since any uncertainty costs money in various forms, hazards of whatever nature or origin affect funds and money flows. Therefore, hazards can irreversibly damage the Entity exposed, without having been materialized.

Problems of hazard qualification will not be discussed in this study. Hazard severity or any other measure of hazard is a h ighly subjective concept, composed of many factors that are mainly associated with human cognitive properties. The perception of hazards and the risk concern are often willingly or unwillingly affected by media (D. Gardner, 2009).

\section{Structure and Company}

As before in (M. Tichý, 2012), two common Entities, Structure and Company, are taken as objects of this study. Attention will be paid to some selected particular concepts of Structural Mechanics, aiming at their transfer into the language of Companies. The Reader is referred to Table 2, where the principal characteristics

Tabel 2. Some characteristics of the two Entities considered

\begin{tabular}{|c|c|c|}
\hline Characteristic & Structure & Company \\
\hline $\begin{array}{l}\text { Basic role } \\
\text { in economy }\end{array}$ & $\begin{array}{l}\text { mainly passive: carrying, sheltering; } \\
\text { consuming money }\end{array}$ & $\begin{array}{l}\text { mainly active: producing goods or } \\
\text { supplying services; generating profit }\end{array}$ \\
\hline System properties & adjustable closed system & adjustable open system \\
\hline $\begin{array}{l}\text { Adaptability } \\
\text { properties }\end{array}$ & $\begin{array}{l}\text { rigid with necessary flexibility and } \\
\text { ductility }\end{array}$ & $\begin{array}{l}\text { flexible and ductile with necessary } \\
\text { rigidity }\end{array}$ \\
\hline $\begin{array}{l}\text { Governing } \\
\text { parameters }\end{array}$ & strength and stiffness & $\begin{array}{l}\text { assets and liabilities; sales and } \\
\text { earnings; liquidity and profitability }\end{array}$ \\
\hline $\begin{array}{l}\text { Environmental } \\
\text { specification }\end{array}$ & specified in physical terms & $\begin{array}{l}\text { specified in economic, social, } \\
\text { and geographic terms }\end{array}$ \\
\hline Components & $\begin{array}{l}\text { carrying members (beams, columns, } \\
\text { foundations); well outlined in } \\
\text { majority }\end{array}$ & $\begin{array}{l}\text { individuals (e.g., employees) } \\
\text { and groups (e.g., management } \\
\text { teams) }\end{array}$ \\
\hline $\begin{array}{l}\text { Links and joints } \\
\text { (internal and } \\
\text { external) }\end{array}$ & tangible; defined & $\begin{array}{l}\text { predominantly intangible; } \\
\text { administrative, managerial, societal; } \\
\text { tangible links and joints exist }\end{array}$ \\
\hline Description & predominantly in physical terms & $\begin{array}{l}\text { predominantly in business, financial, } \\
\text { industrial, and analogous terms }\end{array}$ \\
\hline Calculation models & exact or quasi-exact models exist & speculative models prevail \\
\hline Physical testing & widely used & impracticable \\
\hline Input properties & tested and controlled & $\begin{array}{l}\text { not tested or testable with } \\
\text { difficulties only }\end{array}$ \\
\hline Data availability & $\begin{array}{l}\text { data available in sufficient } \\
\text { quantity and quality }\end{array}$ & $\begin{array}{l}\text { data are scarce, and must be, in } \\
\text { majority, estimated }\end{array}$ \\
\hline Uncertainties & $\begin{array}{l}\text { low degree of uncertainty } \\
\text { and fuzziness }\end{array}$ & $\begin{array}{l}\text { high degree of uncertainty } \\
\text { and fuzziness }\end{array}$ \\
\hline $\begin{array}{l}\text { Research } \\
\text { possibilities }\end{array}$ & physical and theoretical & theoretical \\
\hline Legal aspects & standards and codes of practice & $\begin{array}{l}\text { contracts based on common law or } \\
\text { civil law; regulations }\end{array}$ \\
\hline Lifetime & often longer than expected & often shorter than expected \\
\hline
\end{tabular}


of the two Entities are listed, with no claim to completeness.

Note that Structures are always exposed to hazards of various origin (e.g., tornadoes, terrorist attacks, bad maintenance, misuse), and, similarly, Companies are always subjected to loads (e.g., debts, taxes, fees for legal processing). While hazards to Structures are similar to hazards to Companies, loads on Companies are entirely different from loads on Structures.

Note further: a $\mathrm{S}$ tructure is one of several components of a Constructed Facility, i.e. of a building, highway bridge, tunnel, etc.; a Company is one of many components of the Economic System.

The main features of loads and hazards, important for the examination of the Load/Hazard Analogies are shown in Table. 3. It is generally known that loads can bring a Structure to failure. Hazards affect a Company in similar way. The sole rumors of hazards can have negative contribution to the image of the Company, so that its business health becomes doubtful, and, as a result, the Company's image starts to deteriorate. Banks watch for signs of problems and for possible leaks of internal rumors, and credits and bank sureties might be refused. Hazards of this kind can get materialized; this may stimulate a partial or entire collapse of the Company's business activities, leading to its decline, and finally to its dissolution.

\section{Particular Concepts and Notions}

\subsection{Defects}

The many definitions of defect can be summarized in a simple statement:

A defect is any noxious deviation from the expected properties of a system/object/process that were assumed in its creation and that are expected during its lifetime.
Defects are system properties that can be inherent, inherited, and implanted. A defect-free system does not exist; whether such a statement is true or not, can be neither confirmed, nor challenged. The common quality of defects is randomness. It may be argued that many defects, e.g., those caused by sabotage, violence, or war activities are not random. Yet, even sabotage, street violence, and war are, in the long run, random sociopolitical phenomena.

Sooner or later, due to the presence and development of a s pecific defect, stress and strain gets created in the structural material, with undesired effects on the reliability of the Structure. Therefore, defects can be regarded as a sort of structural loads. Yet, in structural design, defects are never treated in such a way.

Not only material and members may be defective. Defects of the loading process and also defects of use and maintenance are enemies of construction projects.

Any defect, like any load, affects the reliability of the Structure and can result in its partial or total collapse. Defects can be also a cause of loss of
A Company can become defective from its very beginning, or, more exactly, the management processes can be defective even before the Company gets ever set up. Innate defects generate future hazards to the Company, since their existence and possible materialization can be followed by direct or indirect financial loss, be it i mmediate or delayed. Such possibilities are often recognized only too late.

It should be mentioned that the Company itself can be seemingly defect free; nevertheless, defects can be rooted in the environment and, unfortunately, in human decisions. Typically, unfair business practice, which is in fact a market

Table 3. Characteristic properties of structural loads and company-affecting hazards compared

\begin{tabular}{lll}
\hline Property & Loads on Structures & Hazards to Companies \\
\hline General character & tangible; objective; passive & $\begin{array}{l}\text { intangible; predominantly } \\
\text { subjective; active }\end{array}$ \\
$\begin{array}{l}\text { Deterministic } \\
\text { models }\end{array}$ & $\begin{array}{l}\text { physical - well established and well } \\
\text { defined }\end{array}$ & $\begin{array}{l}\text { managerial - scarce and fuzzy } \\
\begin{array}{l}\text { Random } \\
\text { uncertainties }\end{array}\end{array}$ \\
$\begin{array}{l}\text { acceptably described by estimated } \\
\text { probability models }\end{array}$ & $\begin{array}{l}\text { models not available; uncertainties } \\
\text { mainly linked to the character of } \\
\text { business }\end{array}$ \\
\end{tabular}




\begin{tabular}{|c|c|}
\hline $\begin{array}{l}\text { serviceability of the } \\
\text { Constructed Facility. In } \\
\text { structural design, } \\
\text { regulations do not provide } \\
\text { any explicit guidance on } \\
\text { how to deal with the } \\
\text { random nature of defects. } \\
\text { The problem is } \\
\text { covered reactively by } \\
\text { addi- tional reliability } \\
\text { parameters, and } \\
\text { proactively by quality } \\
\text { control at various phases } \\
\text { and levels of construction } \\
\text { projects. }\end{array}$ & $\begin{array}{l}\text { defect, is a dangerous } \\
\text { source of hazards. } \\
\text { That can further result } \\
\text { in internal strains, disputes } \\
\text { and litigation, loss of mar- } \\
\text { ket position, and many } \\
\text { other deleterious } \\
\text { consequences. U nder } \\
\text { specific conditions risk } \\
\text { concern can reach fear or } \\
\text { panic. Hazard feelings } \\
\text { provoked by observed } \\
\text { defects can create } \\
\text { increased risk concern in } \\
\text { Persons involved. }\end{array}$ \\
\hline
\end{tabular}

\subsection{Failure and Collapse}

As soon as a system is borne, it starts its way to gradual decay and final death. In terms of history, the decay may be brief or long. On the route, the system can sometimes fail to meet the requirements set or expected by owners, users, the public, and other individuals or groups interested. Periods exist when a system is close to stopping its service, followed possibly by periods of regeneration. Nevertheless, after having passed all turns and oscillations of development, the system collapses. Depending on the intrinsic properties of the system and its environment, a co llapse can have different forms: e.g., partial or total degradation, ruin.

Under increasing load a Structure goes primarily through a stage when its actual or future normal use is threatened, limited, or entirely restricted. Finally it starts to become out of use. The reliability margin of the structureload system gets consumed, and the Structure collapses either partially or totally.

Two basic modes of structural failure exist: ductile and brittle. Typically, the former failure mode is signaled
There are many obvious causes of a Company failure: bad management, collapse of markets, fraud, corporate crime, and many, many others. Yet, a Company can simply fail by accumulation of hazards. Whenever hazards increase in number and severity, the Persons' risk concern grows and may achieve the distress, dread, and panic levels. At the same time, the risk capacity of the Company gets weakened, and staying in business may become by easy to understand warnings of pending or approaching loss of reliability. Whenever brittle fracture is imminent, no signs of pending disturbances are given to untrained individuals (e.g., users of the Constructed Facility) or even to experienced structural engineers.

A Structure made of brittle material or functioning as a quasibrittle system would collapse at a specific level of load. Yet, at the same load level, a similar Structure made of ductile material properties and subjected to same loads may survive.

\subsection{Progressive Collapse}

Any working stationary or non-stationary system can collapse at an unexpected moment, in an unexpected way, for strange reasons, at surprising conditions, and with unpredictable collapse scenarios. A simple and isolated defect of any kind, tangible or intangible, locally significant or insignificant, can trigger uncontrolled behavior, distributed along timeline and over spaces considered.

In structures, the failure network belonging to the formation of a single defect is characterized by a system of loads and corresponding load effects that differ from those met under defect free conditions. The intensity and arrangement of load effects change because of the spreading structural deterioration. Changes in the carrying system difficult or impossible.

This phenomenon is usually underrated and misjudged; hazards accumulate step-by-step and remain unobserved until the hazard portfolio had reached an unacceptable level. The consequential damage may become excessive. Companies can suddenly collapse without any preliminary warning, or with warnings that are not taken seriously by Persons concerned, particularly by the external ones. Many examples can be given. 
generate further structural reduce its severity. damage, and so a s ort of Typically however, any butterfly effect can start. The process can either get stopped by the properties of the load-structure system or further degenerate up to collapse.

Structures can collapse either gradually or suddenly. In the first case, systems emit significant warnings like cracks, deflections and other deformations; such effects can arouse the sensory system in humans or in man-made indicators construed for this purpose. They can be considered precursors of imminent failure.

\section{Because}

of uncertainties of the input information, architects and engineers are not able to predict, during the design period, all possible failure scenarios. It thus happens that many structural systems fail in an unpredicted and very surprising way. accumulation and regrouping of hazards have a $n$ egative effect upon the internal Persons. As a rule, external Persons can get worried, too. Accumulation and chaining of hazards increase feelings of uncertainty, thus amplifying the existing risk concern. The randomness of hazards and of possible hazard scenarios affects all Persons involved.

To avoid a domino effect in hazard spread, advanced Companies arrange for business continuity management, which, in case of adverse events, ensures an effective response to hazard scenarios predicted, and sets barriers to spread of consequences. The mere existence of Disaster Recovery Plans and similar proactive or reactive documents may have a favorable effect on internal Persons, as far as their hazard feelings are concerned.

\subsection{Instability Problems}

Instability is a concept applied in various branches of science and technology as well as in many other branches - psychology, chemistry, social sciences, in politics. Though the term "instability" has qualitatively different meanings in each branch, the terms stable, metastable, unstable, and indifferent designate the quality of the respective state of equilibrium in whatever, tangible or intangible, connotation.
In Structural Mechanics three basic types of instability are dealt with:

Instability of shape: A load-subjected Structure changes the state of deformations and internal forces in such a way that sudden, sometimes disastrous changes in the system's shape and arrangement ensue.

Instability of position: Because of overload and other reasons, a s tiff part of the carrying system can start moving with respect to its environment; displacements may affect the state of equilibrium and result in toppling, sliding, and submerging or uplift.

Dynamic instability: Under quickly repeated loads structural members and the Structure as a complex can start vibrating. Due to dynamic instability phenomena, the amplitude of vibrations can increase without any increase of the load level.

\subsection{Non-Linearity}

Nothing in the material world happens along a straight line, on a perfect plane, and in a perfect space. Perfect linearity does not exist. Seen from distance, everything is curved, more or less. In the everyday life, nonlinearity is either not recognizable at all or without substantial importance for correct descriptions and assessments of phenomena. However, there definitely are many instances where the non-linearity must not be neglected.

For many reasons, the behavior of any loaded Structure is, in general, non-linear. Although a from the Company's 
perfect linear behavior is non-existent, it is typically one of starting assumptions in Structural Mechanics. Three main sources of non-linearity of the performance of Structures can be recognized:

\section{- material properties}

- geometric properties of the Structure

Combined together, effects of these sources produce a complex pattern of non-linearity. Efficient calculation models covering the non-linearity features are nowadays available in the Structural Mechanics' tool kit; numerical solutions are widely used.

Note here that soil and rock belong to the family of carrying materials. Their properties, definitely non-linear, are often chaotic and thus very close to the substance in which Companies exist. Much experience can be drawn from this fact.

\section{- $\quad$ load properties}

management core or not, may cause severe changes in the comprehensive set of hazards the system is normally exposed to. This is a typical attribute of the non-linear behavior of hazards.

No special or general description of the hazard non-linearity is available. Most hazards and hazard scenarios are too subjective to allow for such a description. Empirical approach is being accepted as entirely sufficient, and the nonlinear amplification of hazard-related problems is tacitly taken as a common fact

The non-linearity of Company's response to hazards is mainly caused by a familiar phenomenon: remedies used in the prevention and in the elimination of the hazards estimated can generate new hazards that can be more severe than the hazards having been removed. Consequently, new risks can arise by the management of hazards itself, since the risk portfolio can change its composition and magnitude in dependence of the properties of the Company system.

\subsection{Constitutive law, Elasticity and Plasticity}

It is generally not known that mathematical models of phenomena governing the behavior of Entities must be based on specific functions, called constitutive laws. Yet, at various levels of everyday communication, many notions that are typically bound to constitutive laws, are met and used.
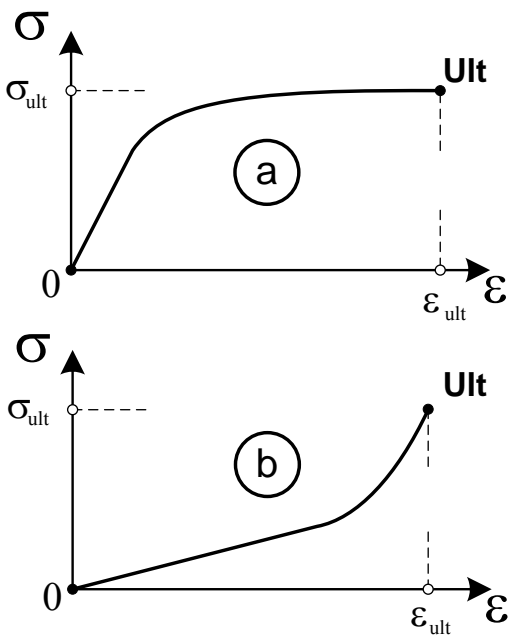

Fig. 1. Stress-strain diagram of a structural material: $\mathbf{a}-$ material softens with growing stress/strain, $\mathbf{b}$ - material hardens with growing stress/strain

Expressions like elastic, plastic, inelastic, elasticplastic, and their derivations typically appearing with scientific and engineering connotations are read and heard in social, business, and other framework.

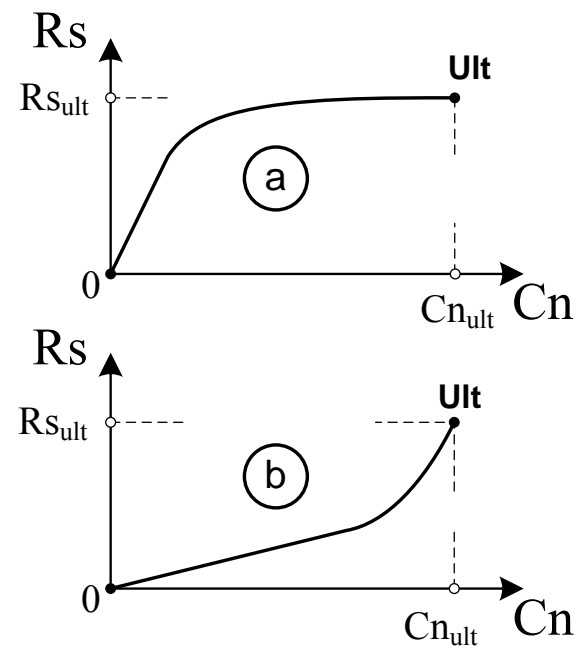

Fig. 2. Risk-concern diagram of a Company: a - risk-averse Company, b - risk-reverse Company; Ult - ultimate risk capacity

E.g., price elasticity and elastic/inelastic demand often occur in business vocabulary; their meaning is obviously very distant from that being perceived in physical context. These notions are used by nonengineers with only a superficial understanding of what they actually mean and what is their actual importance. 
Often the term "elastic" is substituted for "linear", and "elastic-plastic" or "plastic" for "non-linear", or viceversa; such simplifications may get confusing, and should be either avoided or specified. In general, it has always to be taken into account that whatever constitutive laws are proposed and applied, they are estimates of the objective reality, simplified more or less, depending on the problem solved.

Consider a s tructural material the stress-strain diagram, $[\sigma, \varepsilon]$, of which, is shown in simple form in Fig. 1a. It is assumed that there the loading is monotonous up to the ultimate capacity level, $\mathrm{Ult}\left[\sigma_{\text {ult }}, \varepsilon_{\text {ult }}\right]$. The diagram shows a straight segment followed by acu rved segment, and it flattens at increasing stress, $\sigma$, and at increasing strain, $\varepsilon$. In plain words: at the beginning, when the stress in material grows, the strain follows the changing stress almost proportionally. Then, starting from a cer tain level of stress on, the strain increments accelerate, and the particular diagram becomes concave. It seems like the material is yielding to the load.

Another simple diagram is shown in Fig. 1b. There, the curved segment is convex; in other words, the material is resisting the load growth.

In mathematical terms, the two distinct segments of behavior in both drawings are linear and non-linear, respectively.
In the beginning of the operating process of a Company, hazard-related risk and risk-related concern, $\mathrm{Cn}$, remain proportional (see the riskconcern diagram in Fig. 2). The Company management deals with hazards and risks in regular way, and, as a result, the risk acceptability requirements are complied with.

Assume now that the hazard portfolio starts to grow in size and magnitude, i.e., the number of hazards and their subjective severities increase (note that both the number and severity of hazards are subjective quantities). Then,

- a soft Company becomes ductile and yields to hazard accumulation

- a hard Company becomes stiff, defies hazards with less risk concern, but is a 1 ikely candidate for failure without sufficient warning.

Removal of hazards may reduce or entirely remove risks, but in majority of cases this does not remove hazard
The problem gets more involved if also unloading and possibly also reloading processes are taken into account. Fig. 3 shows a very simple case of unloading and reloading. The diagram shows an important particularity: after complete unloading, a certain residual strain, $\varepsilon_{\text {res }}$ , remains in the material.

The diagrams shown in Fig. 1 through 3 are very simplified. They do $\mathrm{n}$ ot say anything about the character of stress (compression, tension), nor do they reflect situations when the load changes from positive to negative, etc.

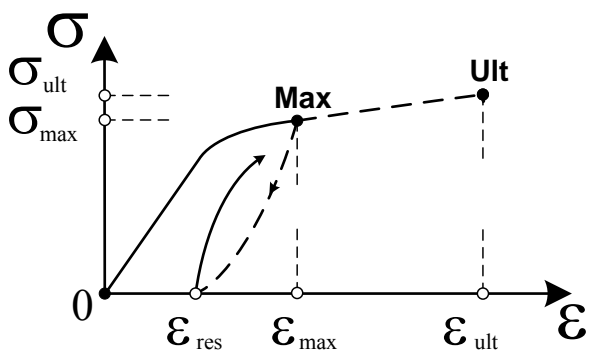

Fig. 3. Stress-strain diagram under loading and unloading; Max - maximum level of load applied, Ult - ultimate capacity possible, $\varepsilon_{\text {res }}-$ residual strain after unloading

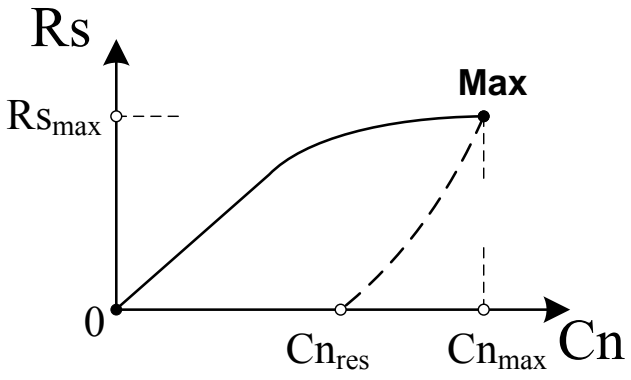

Fig. 4. Risk-concern diagram at occurrence and after removal of hazards (a soft Company case); Max - maximum corresponding to most unfavorable hazard pattern achieved, $\mathrm{Cn}_{\text {res }}$ - residual risk concern 


\subsection{Kinematics and Dynamics}

Wherever movements of solid bodies are possible, two closely related disciplines enter the theoretical models, namely, kinematics that deals with geometric aspects of motion without paying attention to its causes, and dynamics covering the energy aspects of the motion, including properties and behavior of the motion sources. Kinematics and dynamics are encountered in many science fields, starting with astronomy, passing through fluid mechanics, and ending perhaps in the domains of microbiology and psychology.

In Structural Mechanics, solid bodies are often subjected to kinematic and dynamic examination. A Structure subjected to a fast moving load of whatever origin is likely to fail at lower level of load even if the load effects do not achieve their maximum assumed level expected under conditions of continuous and slowly increasing loading. Sometimes, however, the failure level under dynamic loading can be higher than under static load.

The principal backgrounds to these phenomena are changes of the stress-strain function under quickly changing loading rates. This feature governs the dynamic behavior of the loadstructure system in an intermingled way. E.g., phenomena like resonance and damping are typically conditioned by the above properties.
A Company affected by a sudden and unexpected incidence of one or more hazards tends to get damaged earlier than development of the hazard pattern. While, in the latter case, the Company would be able to develop sufficient risk capacity, the sudden occurrence of hazards may affect the available risk capacity in deteriorating way.

Obviously, the respective risk-concern diagram, [Rs, Cn], gets modified under hazard impact (Fig. 5). Though the risk concern does not substantially intensify, higher risks are accepted, and no signals of disastrous hazards and possible linked-up hazard scenarios are felt by Persons involved.

Yet, if hazards change quickly, and their character and severity fluctuate irregularly, the Company is not able to adjust and develop an adequate risk capacity. The phenomena of risk under a slow and continual

resonance and risk damping can be easily identified in the behavior of Companies exposed to dynamic hazards

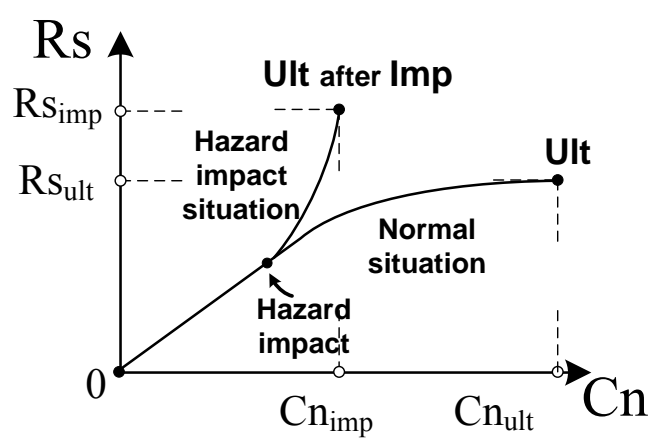

Fig. 5. Risk-concern diagram after hazard impact

\subsection{Fatigue}

Repetitions, regular or irregular, of any phenomenon, tangible or intangible, cause changes in the systems affected. Such changes remain often unnoticed, but they may suddenly surprise individuals or groups concerned. In certain cases even the originating phenomenon can become modified by its own repetitions itself. The summary term for this phenomenon is fatigue; there is obviously no need to explain its meaning.

The process of repeated stress and strain, caused by repeated loadings, affects the strength of material. With certain materials the carrying capacity of the Structure by such process may be not markedly affected. However, many Structures subjected to repeated loading can often fail at lower level of load than it would be achieved at single monotonously growing load. Of course, the maximum level of load governs the phenomenon.

For some materials and
In some Companies exposed to repeated hazards, hazard feelings in Persons get aroused, and the severity of hazards is felt menacing. The ensuing risk concerns grow. The Company gets fatigued of eliminating the repetitive hazards, and can collapse, unexpectedly and prematurely.

On the other hand, many Companies adjust their build-up, so as to develop more risk capacity under repeated hazards during their residual expected lifetime. 
Structures subjected to The strengthening phase repetitions of load, their resistance gets, for a short period, enhanced, but it degrades under repeated loadings later on.

Notions like low-cycle fatigue and high-cycle fatigue are well known in Structural Mechanics. Each of the phenomena is characterized by its specific fracture pattern.

The problems of fatigue of materials and structures is an important issue for structures of various kind.

\subsection{Rheology}

Rheology is a cross-disciplinary science branch that deals with the time-dependent fluid behavior of loaded and unloaded matter. For a rigorous scientist, fluidity is a common property of matter (panta rhei), but in the everyday practice only that matter is examined as fluid, the flow of which can be observed by human sensory tools.

For specific rheological reasons, strain of material subjected to constant stress grows, and, as a r esult, deformations of the Structure increase; this phenomenon is known as creep. Reversely, under constant strain, stress in material decreases; this phenomenon is called relaxation. Moreover, the very strength of material subjected to stress, increasing or not, diminishes with time. Because of these material properties, the load effects in the Structure subjected comes about.

Finally, Companies harassed by repeating hazard occurrences can entirely change their business plans and activities, and even switch to new markets. It depends of course on the frequency and severity of the threatening hazards, and on the adaptability of the individual Company. to a f ixed load are changing. As a rule, the ensuing changes are irreversible, and affect the reliability of the Constructed Facility in general. Because of these effects, rheological phenomena belong to the structural loads category.

Structural Mechanics is able to describe these phenomena and their consequences by exact or semi-exact models with more or less empirical background. Humidity and temperature of the Environment play a significant role in such models.

\subsection{Size Effect}

The effect of size of an object or of a process, natural or man-made of whatever kinds on their general behavior in time and space is a significant factor well known in many areas: in business and politics, as well as in engineering and management sciences, in agriculture, ecology, and in other spheres. Note that the term size can have many meanings: geometric, economic, societal, and other.

Under increasing load, the behavior of a Structure or a s tructural member is affected by their size. The nature of this phenomenon depends primarily upon the properties of the structural material and then also upon the layout of the Structure.

In large-size solid bodies made of homogeneous brittle material, fracture arrives growing risk concern. In this way, the risk capacity weaken. The internal hazard-generated tensions are time-dependent; they either develop or, quite the reverse, fade in time.

Because of the creeping development of hazard-indifferent, or even hazard-blind; this results in carelessness and in ignoring any direct or indirect warnings. Behavior of individuals in war zones shall be mentioned here. Similarly, people are getting apathetic about terrorist threats. of the Company can hazards, Persons get often
In a given business environment, the behavior of large Companies is in many aspects substantially different from that of small Companies. Company's readiness to deal with hazards and risks, flexibility, willingness to diversification, and many other properties affect its conduct in the environment in dependence on Company's size. Note that the notion whose organization, location, business plan, parameters have been stabilized in time. Because of rheological phenomena, timedependent long-time changes of components, i.e., units, links, and joints, happen. However, they always get observed with certain delay. Persons involved start to perceive such changes and take them as sources of intensifying hazards; this obviously results in 
statistically at lower loads than in bodies of small size. However, if the material is ductile, possibilities of sudden failure become less prominent, and the respective Structure can survive an increase in load, even when one or more carrying members had been already damaged.

Time and space conditions play an important role both in brittle and ductile materials. Note that space in Structural Mechanics is, as a rule, geometric.

For detailed information on size effect and related problems see, e.g., (Z. P. Bažant, 2002) and (X. Z. Hu \& K. Duan, 2010).

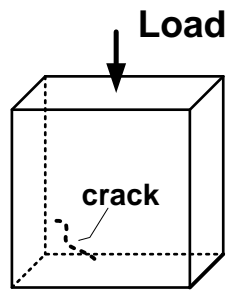

(a) of size may have different meanings. Further, not only the business size of the Company may govern its behavior: the size of the customers, of the field of activities, etc. may have a dominant effect.

It cannot be asserted that large size Companies are more flexible than small ones. It depends on the Company's build-up, whether upside or downside features of the size effect prevail. While some large Companies may be typically less sensitive to hazards than small ones, the contrary is often true. Large size may have negative effect on the risk capacity.

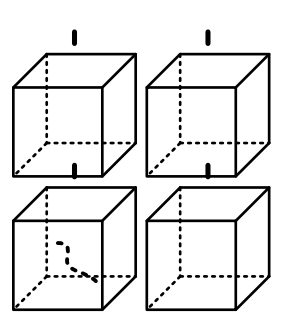

(b)

Fig. 6. Size effect, Structure of brittle material

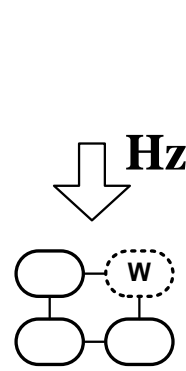

(a)

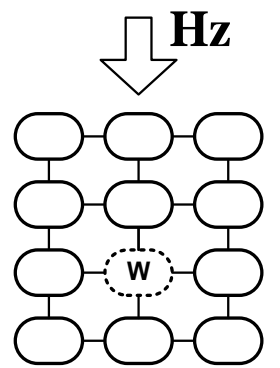

(b)
Fig. 7. Size effect, Company exposed to hazard; a - small company, failure of one weak element can be catastrophic, $\mathbf{b}-$ large company can survive
Figs. 6 and 7 may help understand the analogy of the size effects in Structures and Companies. Under a certain level of load, a local crack can cause failure of a large body (Fig. 6a). In an assembly of small bodies (Fig. 6b), the member with the crack will fail under the same level of stress as in the body in Fig. 6a, while the other members will reach higher stress levels. Thus, the mean level of failure stress (strength) will be higher for sets of small bodies than for a large body. Size has a unfavorable effect in this case. In a s mall Company (Fig. 7a), the failure of a weak component, $\mathbf{W}$, may have disastrous consequences, while (Fig. 7b) a w eak component may not affect the existence of a 1 arge Company in its entirety. Size has a favorable effect in this case. It all depends on what is the meaning of size in the particular case considered.

\section{General Remarks}

The ten analogies presented above show that concepts and notions frequent in the domain of Structural Mechanics have their parallels in the domain of Risk Analyses. The above list is far from being complete, and each item can be further elaborated in detail. It is obvious that the basics of the Load/Hazard Analogies concept proposed in (M. Tichý, 2012) can be further extended, and fundamentals of the Entity Risk Mechanics can be built up.

Concrete notions of Structural Mechanics are transferred to the domain of abstract notions related to the behavior of Companies or of other non-engineering Entities exposed to tangible or intangible hazards coming from various sources. The transfer flows in one direction, i.e., from concrete to abstract (Fig. 8). The transfer concept proposed is similar to that applied in the description of the development of languages; see (G. Deutscher, 2005).

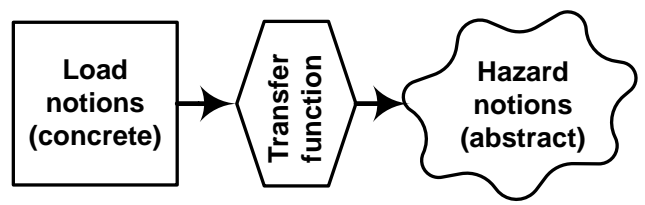

Fig. 8 - Transfer of concrete notions to abstract notions

The route from the first perception of a hazard to the evaluation of the respective risk can never become straightforward. It even happens that the speculative 
process gets not finalized at all, since necessary data and models are missing. The Load/Hazard Analogies concept might stimulate solutions which would otherwise escape the attention of risk analyzers.

At the present stage of development it is obviously not possible to formulate analytical models of Entity Risk Mechanics, ERM, that would transfer the engineering knowledge of load subjected Structures to hazard exposed Entities. The availability of such models seems rather remote even in close futurity. However, the mere understanding of the transfer of notions may affect and improve the thinking of experts, and stipulate development of new ideas.

The way to a complete system of ERM will logically be lengthy and tedious. Nevertheless, the possibilities offered by the Load/Hazard Analogies are, in the Author's opinion, wide-ranging and promising.

\section{Conclusions and Suggestions}

(i) The basic analogies between load-subjected Structures and hazard-exposed Companies, identified in (M. Tichý, 2012), can be further developed and extended to specific problems of the two Entities examined.

(ii) The Analogies discussed and many others can be helpful in case of special problems of Risk Management and Risk Analysis, like those of risk allocation, risk prevention, insurance decisions, risk forecasting, and others.

(iii) A structural engineer, when properly instructed and guided, would discover unexpected hazards and hazard scenarios of the project even if their sources were beyond the construction domain.

(iv) At the beginning of the project decision stage, it may be sensible to include into the body of experts a structural engineer experienced in Structural Mechanics as a cross-thinking help.

(v) Since engineering systems of any type (transport, electrical, and others) are subjected to loads, and all social, economic, educational, and other nonengineering Entities are exposed to hazards, the concept of Load/Hazard Analogies can be used in many other load-subjected/hazard-exposed Entity tuplets.

(vi) Empirical and speculative research is necessary to develop concepts of ERM in full. In particular, study of the risk-concern function, [Rs, Cn], shall be prioritized.

\section{Acknowledgements}

The Author would like to thank Professor Jiří Šejnoha, Czech Technical University, for his insightful suggestions concerning some aspects of the analogies presented. However, any errors of whatever kind are my responsibility.

\section{References}

M. Tichý, Entity Risk Mechanics, J. of Risk Analysis and Crisis Response. 2(2) (2012), 107-113.

C. Starr, Social benefit versus technological risk, Science, 165 (1969), 1232-1238 (adapted from a symposium paper presented by Starr in 1968).

S. Kaplan and B. J. Garrick, On the quantitative definition of risk, Risk Analysis, 1(1) (1981), 11-27.

S. Kaplan, The words of risk analysis, Risk Analysis, 17(4) (1997), 407-417.

H. Merkelsen, The constitutive element of probabilistic agency in risk: a semantic analysis of risk, danger, chance, and hazard. J. of Risk Research, 14(7) (2011), 881-897.

D. Gardner, Risk. The Science and Politics of Fear (Virgin Books, London, 2009).

J. Schijve, Fatigue of Structures and Materials, 2nd edn. (Springer, Berlin, 2009).

Z. P. Bažant, Scaling of Structural Strength (Butterworth-Heinemann, London, 2002).

X. Z. Hu and K. Duan, Mechanism behind the size effect phenomenon, J. of Eng. Mechanics ASCE, 136(1) (2010), 60-68.

G. Deutscher, The Unfolding of Language (Arrow Books, London, 2005), 115-143. 